\title{
Quantifying model errors using similarity to training data
}

\author{
Rob D Brown ${ }^{1 *}, J D$ Honeycutt ${ }^{1}, S L$ Aaron $^{2}$ \\ From 5th German Conference on Cheminformatics: 23. CIC-Workshop \\ Goslar, Germany. 8-10 November 2009
}

When making a prediction with a statistical model, it is not sufficient to know that the model is "good", in the sense that it is able to make accurate predictions on test data. Another relevant question is: How good is the model for a specific sample whose properties we wish to predict? Stated another way: Is the sample within or outside the model's domain of applicability or what is the degree to which a test compound is within the model's domain of applicability. Numerous studies have been done on determining appropriate measures to address this question [1-4]. Here we focus on a derivative question: Can we determine an applicability domain measure suitable for deriving quantitative error bars - that is, error bars which accurately reflect the expected error when making predictions for specified values of the domain measure? Such a measure could then be used to provide an indication of the confidence in a given prediction (i.e. the likely error in a prediction based on to what degree the test compound is part of the model's domain of applicability).Ideally, we wish such a measure to be simple to calculate and to understand, to apply to models of all types - including classification and regression models for both molecular and non-molecular data - and to be free of adjustable parameters. Consistent with recent work by others $[5,6]$, the measures we have seen that best meet these criteria are distances to individual samples in the training data. We describe our attempts to construct a recipe for deriving quantitative error bars from these distances.

\section{Author details \\ ${ }^{1}$ Accelrys Inc, 10188 Telesis Court, San Diego, CA 92121, USA. ${ }^{2}$ Accelrys Inc, Cambridge, UK.}

Published: 4 May 2010

${ }^{1}$ Accelrys Inc, 10188 Telesis Court, San Diego, CA 92121, USA

\section{References}

1. Eriksson L, Jaworska J, Worth AP, Cronin MTD, McDowell RM, Gramatica P: Methods for Reliability and Uncertainty Assessment and for Applicability Evaluations of Classification- and Regression-Based QSARs. Environmental Health Perspectives 2003, 111:1361.

2. Tropsha A, Gramatica P, Gombar VK: The Importance of Being Earnest: Validation is the Absolute Essential for Successful Application and Interpretation of QSPR Models. QSAR Comb Sci 2003, 22:69.

3. Jaworska J, Nikolova-Jeliazkova N, Aldenberg T: QSAR applicabilty domain estimation by projection of the training set descriptor space: a review. Altern Lab Anim 2005, 33:445-59.

4. Stanforth RW, Kolossov E, Mirkin B: A Measure of Domain of Applicability for QSAR Modelling Based on Intelligent K-Means Clustering. QSAR \& Combinatorial Science 2007, 26:837-

5. Sheridan RP, Feuston BP, Maiorov VN, Kearsley SK: Similarity to Molecules in the Training Set Is a Good Discriminator for Prediction Accuracy in QSAR. J Chem Inf Comput Sci 2004, 44:1912.

6. Horvath D, Marcou G, Varnek A: Predicting the Predictability: A Unified Approach to the Applicability Domain Problem of QSAR Models. J Chem Inf Comput Sci 2009, 49:49.

\section{doi:10.1186/1758-2946-2-S1-07}

Cite this article as: Brown et al:: Quantifying model errors using similarity to training data. Journal of Cheminformatics 2010 2(Suppl 1):07.

\section{Publish with ChemistryCentral and every scientist can read your work free of charge \\ "Open access provides opportunities to our colleagues in other parts of the globe, by allowing anyone to view the content free of charge." W. Jeffery Hurst, The Hershey Company. \\ - available free of charge to the entire scientific community \\ - peer reviewed and published immediately upon acceptance \\ - cited in PubMed and archived on PubMed Central \\ - yours - you keep the copyright \\ Submit your manuscript here: \\ http://www.chemistrycentral.com/manuscript/

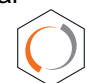 Chemistry Central}

